\title{
"Nos llevó el ensanche": Medellín en las novelas urbanas de Manuel Mejía Vallejo
}

\author{
"Nos llevó el ensache": Medellín in the Urban Novels of \\ Manuel Mejía Vallejo
}

\section{Resumen}

Entre 1973 y 1987 Manuel Mejía Vallejo publicó una serie de novelas urbanas donde puede leerse una imagen de la ciudad de Medellín. En este trabajo se hace una lectura de la ciudad escrita en estas novelas atendiendo a tres elementos que el análisis nos revela como centrales: el progreso, el desalojo y la nostalgia. Desde aquí se planteará cómo para este escritor la urbe ha sido arrasada, el ciudadano se ve atropellado y borrado simbólicamente por el ensanchamiento de calles y la demolición de barrios. El recuerdo es la única salida que los personajes encuentran a esta situación que los deja por fuera de las lógicas de una ciudad que progresa y se moderniza.

Palabras claves

Manuel Mejía Vallejo, Medellín, ciudad, recuerdo.

\begin{abstract}
The Colombian writer Manuel Mejía Vallejo published between 1973 and 1987 a series of urban novels about the image of his city: Medellín. This paper analyzes the narration of urban space around three central motifs: progress, uprooting and nostalgia. It also studies how the novelist narrates the symbolic erased of the citizen and the devastation of the traditional city due to the expansion of the streets and the uncontrolled demolition of the neighborhoods. For the characters of these novels, memory is the only way to maintain their identity within the logic of a modern city.
\end{abstract}


Estas calles se torcieron para respetar un árbol, se emperifollaron para llegar a los magnates, se avergonzaron para pisar suburbios.

MMV

Hace unos días buscaba en internet qué querían decir ciertas siglas de un cartel que despertó mi curiosidad. En cuanto escribí en el buscador "cartel” la primera sugerencia que me entregó fue "Cartel de Medellín”. No me sorprendí, en mí siempre se da una cierta desilusión cuando estas coincidencias me asaltan, me resulta imposible desprender mi identidad de esa urbe del valle de los aburrá, pues allí nací. Pensé entonces que Medellín se ha visto arrasada varias veces por diversas circunstancias, aunque algunas hayan dejado una marca más profunda y las grandes productoras sigan alimentándose de ello, ayudando a consolidar el imaginario que el resto del mundo tiene de la ciudad. Basta con mirar el rostro de otra persona cuando usted le revela que es originario de allí para darse cuenta de la curiosidad, el temor y cierta complicidad que surgen entre ambos. De repente uno se ve envuelto en una situación compleja donde ni usted ni su interlocutor saben qué se debe decir a continuación, hay que tomarse un tiempo para conseguir superar el dilema y que la conversación pueda retomar algún camino. Esta mezcla de sentimientos es Medellín, siempre florecida, siempre emprendedora, siempre amada y repudiada, siempre convulsa y violenta, pero nunca exactamente la misma. Como sucede con cualquier ciudad latinoamericana, la historia de Medellín es un cúmulo de cambios que se caracterizan por ser muy rápidos, radicales y con grandes repercusiones sociales. Pasamos de vivir en la "capital industrial y comercial de Colombia", en la "tacita de plata" o la "ciudad de la eterna primavera", a morar en el infierno de "Metrallo", un túnel oscuro que para algunos vuelve a divisar algo de luz bajo el amparo de discursos polémicos en torno a la educación, el emprenderismo, la arquitectura y la moda. Los cambios de la ciudad vienen siempre abanderados por dos asuntos: la violencia y el progreso, a veces los propósitos se cruzan, a veces prima uno sobre el otro, aunque realmente ambos mantienen su 
presencia en el transcurrir de la urbe, a la cual cada dos por tres se la "lleva el ensanche" o, mejor, se la "lleva el Putas"1.

Manuel Mejía Vallejo nace en 1923 y muere en 1998, pertenece a una generación de colombianos que nació en el campo, vivió su infancia en el pueblo $\mathrm{y}$, al comenzar la juventud, llegó a la ciudad donde transcurrió casi el resto de su vida. Estas personas, hijas de las primeras décadas del siglo XX, han asistido a una Medellín en constante transformación. Sus antepasados la conocieron siendo la Villa de Nuestra Señora de la Candelaria de Medellín (1675-1813), ellos ayudaron a su consolidación como capital industrial, sufrieron la violencia bipartidista (1948), la de las guerrillas (1960), la del narcotráfico (1980), y hoy ven cómo sus nietos y bisnietos trabajan por una ciudad de discursos fracturados que sigue jugando al ritmo de los grandes capitales mientras unos pocos le apuestan a iniciativas pequeñas, pero significativas, que intentan pensarla en consonancia con el medio ambiente, las políticas de género, la interculturalidad, la apropiación del espacio público y un proceso de paz con el grupo guerrillero más antiguo de la historia del país (FARC-EP). Este trabajo se focaliza en la ficcionalización que hace Mejía Vallejo de la Medellín de los años 70, donde nos muestra los efectos que la modernización de la primera parte del siglo genera en la ciudad. Para ello revisaremos las novelas Aire de tango (1973), Las muertes ajenas (1979), Y el mundo sigue andando (1984) y La sombra de tu paso (1987). En estos textos el autor nos presenta una ciudad mirada desde la nostalgia, el desarraigo y el desconcierto causado por una modernización acelerada, descontextualizada y lejana a los intereses de las personas que habitan sus calles día a día.

\footnotetext{
${ }^{1}$ Las expresiones "nos llevó el ensanche" y "nos llevó el Putas" son comunes en el habla coloquial de los paisas o antioqueños (gentilicios de los originarios del departamento de Antioquia, cuya capital es Medellín). La primera hace referencia a que algo desaparece o fue demolido al momento de ampliar una calle, su uso se hizo frecuente después de la modernización de la ciudad a principios del siglo XX. La segunda, "nos llevó el Putas", puede traducirse como "nos llevó el diablo o el que más poder tiene". El "Putas" es un personaje de la mitología antioqueña que representa al espíritu del mal, a quien se le acreditan muchas cualidades similares al ideal del antioqueño (picardía, buen negociante, parrandero, hábil de palabra, conquistador, etc.). Entre los arrieros de las montañas de Antioquia se hablaba del "Putas de Aguadas" como el más célebre en negociar, engañar y hacer maldades a otros.
} 
Las obras que hemos elegido se pueden considerar como parte de aquello que los críticos han denominado la "novela urbana" colombiana, término que usan para diferenciarlo de la "novela de la ciudad", donde este espacio no es más que un territorio físico, un escenario, un paisaje con calles, monumentos y sitios concretos que se quedan en el terreno de lo alegórico o de una simple ubicación cartográfica. En contraste, la ciudad de la "novela urbana" se relaciona con el mundo interior del personaje, se organiza según una estructura ideológica, un conjunto de significados, se convierte en un elemento central en el cual se despliegan elementos culturales e imaginarios. En un artículo sobre esta temática, Clara Victoria Mejía considera que la novela colombiana abandona tópicos como el enfrentamiento entre civilización y barbarie, o el de escritura y oralidad, que pueden apreciarse en novelas como María (1867) o La vorágine (1924), en el momento que comienza a pensar la ciudad como un espacio que trasciende lo propiamente geográfico (71). La variación en el tratamiento de dicho espacio coincide con el crecimiento de las metrópolis y los cambios habitacionales que ello implica, ante los cuales no permanecen indiferentes los diversos saberes humanos. La ingeniería, la arquitectura, la geografía, las ciencias sociales y humanas se ven llamadas a pensar en la urbe como una pregunta ineludible para entender la vida del hombre contemporáneo. La ciudad puede asumirse como edificación, ejercicio espiritual, lenguaje, carne, caleidoscopio, entorno paisajístico, idea, sueño, espejismo, realidad, calles, imagen, tecnología, sonido de automóviles, espejo, artificio, estado del alma. Podríamos continuar este derrotero casi de manera infinita, pero lo que nos interesa es situar cómo estas reflexiones se plasman en la narrativa, por ejemplo en un París cantado por Baudelaire, por Proust o por Cortázar; en la creación de Comala y Macondo; o en la ciudad caminada por Leopold Bloom. Esta forma de la novela trasciende el diseño de un escenario para crear un espacio-tiempo mucho más complejo que da cuenta de una estrecha relación entre el hombre, su concepción vital y el lugar que habita. Son narraciones que permiten entender que cada persona construye su ciudad, tal como explica Armando Silva: 
La ciudad aparece como una densa red simbólica en permanente construcción y expansión. La ciudad, cada ciudad, se parece a sus creadores, y éstos son hechos por la ciudad. No se diría con exactitud que somos ciudadanos del mundo: más bien somos ciudadanos de una ciudad que habita el mundo. Lo que hace diferente a una ciudad y otra no es tanto su capacidad arquitectónica, visión rezagada luego de un modernismo internacional y unificador en avanzada crisis, cuanto más bien los símbolos que sobre ella construyen sus propios moradores. Y el símbolo cambia como cambian las fantasías que una colectividad despliega para hacer suya la urbanización de una ciudad. (23)

En el marco de este tipo de acepciones se inscribe la ciudad escrita por Mejía Vallejo, ante todo un espacio simbólico, íntimamente ligado a quienes lo habitan, particularizándolo con sus historias y miradas. En su obra, Medellín es un espacio creado y dirigido por seres humanos, cada pedazo de la urbe está dotado con unos valores particulares, el lugar no solo hace referencia a una disposición física de los objetos sino que también refleja sentires, temores, ideologizaciones, deseos: "Nuestros pasos seguían entre mil pasos de transeúntes, viajeros sin para qué de la tarde a la noche. El reloj de La Basílica soltaba sus horas para nadie, para todos, un revuelo de palomas al sonar en la torre alta, miradas que se les unían" (La sombra 47). El espacio se configura a partir de un imaginario cultural, su existencia nunca es completamente real en el sentido objetivo, ella depende en gran medida de elementos subjetivos que se le asignan a partir de la experiencia vital de una persona o un grupo. En consonancia con Gaston Bachelard, entendemos que "el espacio captado por la imaginación no puede seguir siendo el espacio indiferente entregado a la medida y a la reflexión del geómetra. Es vivido. Y es vivido, no en su positividad, sino con todas las parcialidades de la imaginación" (Espacio 28). La urbe es entonces poética, está hecha de palabra, tiene la lógica del lenguaje, se construye y reconstruye diariamente, necesita de la memoria para mantenerse en el tiempo. 
Luz Mary Giraldo argumenta cómo en las novelas urbanas, entre las que incluye las de Mejía Vallejo, la imagen de la ciudad cambia "al pasar de representación de mundo ideal a mundo real y degradado; de mito deformante a realidad cultural; de espacio arquitectónico a forma de vida; de disolución de la identidad a descentración y pulverización del sujeto; de espacio citadino a mundo imaginario" (xvii-xviii). Mejía Vallejo recrea la ciudad durante la década del 70 lejos de la ciudad idealizada, Medellín es narrada como un espacio deteriorado arquitectónica y moralmente por la industrialización, la violencia y la modernización:

La ciudad ruidosa y presuntuosa no corresponde a sus gentes, creció a un ritmo más acelerado que la conciencia de sus habitantes; estos de pronto se sintieron extranjeros, desplazados, esclavizados, desorientados dentro de su alma campesina, aldeana, provinciana; y a grandes problemas que exigían grandes soluciones -alumbrado y acueducto, urbanización e industria- se enfrentaron en un principio con remedios de parroquia, sin férrea voluntad de crecimiento. (Las muertes 208)

Los textos nos revelan una Medellín que desmantela los espacios que han trazado su carácter para dar paso a los avances técnicos y cumplir con los requerimientos de una ciudad moderna: "Después de años y años, polvo en los huesos, destierro de la selva, huida del aborigen, edificaciones, polvo, polvo, polvo..." (299). Ese pueblo que crece en un estrecho valle intenta ampliarse transformando los caminos en calles y las calles en avenidas, quienes piensan en el ordenamiento territorial parecen tener como prioridad el paso de los pocos automóviles de la época sin importar que se entorpezca el caminar de las personas. Es por ello que la imagen del ensanche de las calles, el ensanche que se lleva a quienes habitan el lugar, funciona en los textos como una de las metáforas más potentes para nombrar el sentimiento de ser arrasado por planificaciones y construcciones que responden a intereses particulares y ajenos. 


\section{En nombre del progreso: justificaciones de una ciudad que se moderniza}

Desde el momento en que Medellín se concibe como ciudad, renunciando a ser una villa o un pueblo, se inserta en la lógica de la modernización que busca llegar a industrializar y tecnificar todos los procesos urbanos intentando cumplir con los parámetros de lo moderno. Las ciudades quieren ser los grandes centros de poder, administración y desarrollo económico, en este sentido deben consolidarse como espacios con un sistema modernizado, es decir, que consolide una compleja diferenciación de la estructura política, que se defina como democrático, burocratice sus prácticas y trabaje por la acumulación de riqueza. En la narrativa urbana de Mejía Vallejo se puede entender cómo lo moderno y su gran caballo de batalla (la idea del progreso), encajan entre los imaginarios de un pueblo que se ha fundado en medio de la lucha contra la naturaleza, que surge de la fuerza y la terquedad de familias que decidieron dominar la montaña andina. Para la población que se asentó en los primeros pueblos antioqueños, la idea de salir adelante tiene un sentido fundante, no hay posibilidad de considerar el retroceder o el quedarse quieto, la mirada está puesta en un espacio que está por venir, como si se continuara observando la cima aún no conquistada se apunta a un futuro que aún no llega: "Verraca ciudad esta, crece p'arriba, tumbar para que crezcan estas ciudades y estas casas grandes. Vea, le dije, echar p'arriba es lo que hace falta, ¡hombre!” ( $Y$ el mundo 78). En nombre del progreso se abrió la montaña, se fundó, se consolidó la industria, se derrumbó el patrimonio para dar cabida a los nuevos pobladores: hombres y mujeres del campo que llegan escapando de la violencia, la pobreza y buscando una vida mejor donde poder sacar adelante la familia. Paradójicamente, una vez más, el progreso actúa como ideal.

Mejía Vallejo relata la ciudad a través del sentir de estas personas que han dejado sus tierras y costumbres campesinas buscando un lugar que los refugie, que los defienda de las guerras bipartidistas y les dé un empleo en la reciente industria para mejorar su nivel de vida: “-«Aquí gano dos pesos al día»-habías dicho-, «en 
la ciudá pagan a ocho con cincuenta». / Pero en la ciudad no podías tener matas de plátano y yuca, maizal, huerta, huevos de cuatro gallinas, un gurre, una pava, un cusumbo de cacería. / -«Allá trabajan ocho horas, aquí trabajo catorce» / -«En la ciudá no amenazan tanto, allá no matan ni boletean tanto»” (Las muertes 296). La idea de que en la ciudad se vive mejor viene acompañada de un cambio de valores. La tierra que daba frutos y hortalizas deja de tener el primer lugar en la concepción de una vida digna, el trabajo agrícola se ve cuestionado por la concepción de riqueza asociada al capital, donde cada hora de trabajo debe traer mayor ganancia monetaria. El dinero se convierte en el principal bien y este se adquiere con el empleo industrial, no con la labor del campo que, además de desarrollarse en medio de un conflicto armado, no trae el mismo tipo de ganancia. Desde esta perspectiva, Medellín se inserta por completo en el proyecto de tecnificación y desarrollo industrial según los estándares de aquellos países que se consideran ricos, a los cuales perfila como sus modelos a seguir: "Progreso era mostrarse, por imitación, semejantes a gentes y países que habían creado progreso" (La sombra 43). La ciudad constantemente ha vivido en un intento de ponerse al día en este sentido, pero nunca lo ha conseguido totalmente, las reformas se hacen en beneficio de las élites y ello permite que siempre algo se escape. Una urbe que en las últimas seis décadas había multiplicado por doce su población con las migraciones del campo (Melo 28) intenta responder a la necesidad de crecimiento con proyectos que no incluyen a todos los que están y mucho menos a los que van llegando, hecho que producirá una gran cantidad de contrastes:

Junto al taller de fundición o la fábrica de helados sobrevive el primitivo horno del alfarero y la rueca de las viejas comadres; cerca de las universidades con modernas aulas y laboratorios, se tienden consejas campesinas y ritos de antigua magia; mientras el científico investiga en su gabinete, el vendedor de específicos, serpiente al cuello, expende en suburbios yerbas y brebajes. Torres de acero y alumbrado a vela, obeliscos y vara de premio, rascacielos y chozas, mulo y reactor, puente monumental 
y guaduas atravesadas sobre el río, camiones y carretas, grúas y zorreros, opulencia y miseria, sabiduría e ignorancia, santidad y vicio, de la sombría esclavitud y del costoso libertinaje. (Las muertes 209)

Poco a poco las novelas van mostrando cómo la ciudad muda su rostro para entrar en la vanguardia de las ciudades del momento, sin tener en cuenta los modos de vida y los sentidos de un número significativo de personas, pues ello supondría revisar otro conjunto de valores que impiden la acumulación de riqueza. Hay un aspecto que ayuda a la consolidación de esta perspectiva del progreso y es el mito de la raza antioqueña, un ideal construido desde el siglo XVIII en el cual se determina que el antioqueño o paisa cumple con unas características particulares: "Un hombre blanco y varonil, independiente, austero en el gasto, pragmático e ingenioso; un trabajador infatigable, con moral de hierro, que a pesar de sus arduas tareas nunca olvidaba afeitarse cada mañana" (Gallego, párr. 7). Las raíces indígenas y africanas quedan por fuera de esta imagen, que además se complementa con la de la familia tradicional, donde la mujer ocupa el lugar de la cocina, cuidando la imagen de su marido y vigilando la educación de los hijos. Se configura así la idea de una sociedad patriarcal, donde se debe trabajar incansablemente para conseguir riqueza, riqueza que hay que cuidar y no dilapidar, pues de ella depende el lugar que se ocupa social y políticamente. Es así como en el marco nacional, la identidad de quienes son de Medellín está asociada a un afán de hacer dinero, el trabajo y la producción industrial tienen prioridad sobre cualquier problemática social porque permiten el crecimiento: "Hasta qué punto somos negocio [...] Los negocios han hecho la gran ciudad, las grandes fábricas, los grandes almacenes; anuncios y más anuncios recalcan la obligatoriedad de entrar en el negocio humano [...] El canto a la monumentalidad, a la audacia, al progreso, al monopolio" (Las muertes 206). El espacio público se planifica y construye asociado a esta visión social donde hay clases superiores cultural y políticamente, todos sus elementos se supeditan a los intereses comerciales, en especial los de aquellos apellidos dueños de las empresas más rentables: "Eran casas viejas, las compró una empresa muy rica. Y otra construcción como exhibicionismo: el que más tiene, el que más sube, 
el que más grita. Entonces a la Empresa Industrial le asiste el derecho de adquirir para derruir el patrimonio colectivo. $\mathrm{Y}$ al arquitecto el derecho de tumbar lo que viene tumbando por razones de retribución económica" ( $Y$ el mundo 79). Las personas que no se acogen o van contra los planes de estas intervenciones urbanas son dejadas por fuera, se las relega a las laderas de la montaña en barrios periféricos o quedan recluidos en unas pocas calles céntricas, en el conocido barrio de Guayaquil.

Para nuestros personajes Guayaquil es su espacio vital, allí llega el ferrocarril que los ha traído de los pueblos, allí están las cantinas y los bares donde se han encontrado con otros semejantes y se escucha la música popular (bambuco, cumbia, tango). Es una zona en la que conviven diversas formas de vida, de día funciona el mercado y el comercio, en la noche caminan por sus calles prostitutas, homosexuales, cuchilleros, adictos al juego y a las drogas, tal y como se explica en este fragmento:

Los forasteros, casi todos sin fortuna, atraídos por la prosperidad de Medellín, habitaron casuchas y piezas húmedas y estrechas, o se sumaron a la incontenible nube de langostas que se adueñó de calles y plazas. Fueron asociados al barrio Guayaquil. [...] Guayaquil fue un centro en sí, el lugar donde el capitalismo mostró su fuerza, y donde muchos habitantes de Medellín sobrevivieron sin necesidad de ir a otros sitios de la ciudad.

Alrededor de este mundo de la compra y la venta aparecieron los más inverosímiles personajes, que además de intercambiar mercancías, generaron la circulación de otros valores, creencias, mitologías y formas de pensar. Obispos y gobernantes reforzaron sus discursos sobre la moral y las buenas costumbres. Palabras cargadas de asepsia, rumores de maldición y mitología del infierno se esparcieron por los labios de los moralistas e higienistas, preocupados porque este barrio no aceptó, como ellos quisieron, sus preceptos sobre el valor de la religión católica, el trabajo y el ahorro, banderas de la pujante raza paisa. [...] Instados a rezar, 
producir y ahorrar, prefirieron conjugar verbos diferentes. Nacer, despilfarrar, robar, cargar, beber, copular, pelear, matar y pedir marcaron el rostro de seres anónimos que maduraron a Guayaquil, barrio de amores y odios, nacido en Medellín en las dos últimas décadas del siglo XIX. (Betancur, xix-xxi)

El barrio es un lugar que puede ser peligroso para el que no conoce sus lógicas. Ese conjunto de calles alrededor de la plaza Cisneros es un espacio híbrido, tejido por quienes se encuentran a medio camino de la ciudad y el campo, aquellos que no pudieron ser educados en las normas de lo urbano, en esas nuevas formas de ser y actuar que propone una ciudad moderna (Orrego 88). Guayaquil representa ese lugar que el campesino consigue hacer suyo una vez se adapta a la ciudad. Este proceso podemos verlo en nuestros personajes, quienes sufren por el desarraigo de sus costumbres, sintiendo una gran nostalgia por su pasado pero, al mismo tiempo, intentan insertarse en las lógicas de la ciudad y apropiarse de ellas; con los años lograrán sentir que pertenecen a la ciudad, que una parte de ella la han hecho suya: "Pero si el camino se hace calle y la calle pueblo y el pueblo ciudá, ¿quién retrocede? Tal vez mejor lo que se fue dejando, pero si uno ha entrado en conversas va perdiendo el trique de la soledá" (Mejía Vallejo, Aire 43). El asunto se plantea con mayor complejidad cuando esa urbe que ahora identifica a aquellos que eran migrantes también comienza a desaparecer, se derrumban casas para ampliar espacios, se construyen grandes edificios, se reemplazan los medios de transporte y de comunicación. Los personajes se encuentran constantemente escindidos entre el pasado y el presente sin posibilidad de arraigarse a nada (Fonnegra 58). Para ellos habitar es una incansable lucha por no desaparecer que comienza cada vez que la ciudad da un paso por alcanzar los ideales de la metrópoli moderna.

Guayaquil es conquistada por los grandes comerciantes. El plan territorial de una urbe que progresa obliga a transformar este lugar, darle un aspecto nuevo, mejorar su oferta de mercado y ampliar sus callejuelas para que puedan entrar los automóviles: "Aquí funcionaba la runfla de cafés de punta y raya. Fíjese ahora, talleres, agencias de autos, almacenes de repuestos, ferreterías. ¡Cuántos cuchillos 
mansitos en las vitrinas!" (Mejía Vallejo, Aire 19). La construcción de un edificio, la remodelación de una tienda, un incendio dudosamente accidental o el traslado de una fábrica son los motivos que justifican esas modificaciones del paisaje. El progreso aparece como una razón de peso suficiente para modificar o intervenir todo aquello que se considere necesario, la prioridad que se le da a este tipo de transformaciones está avalada por la idea de salir adelante. Estos personajes que caminan por Guayaquil gastando un salario en licor, invirtiendo su tiempo en conversaciones de cantinas y peleas callejeras no se contemplan como parte del nuevo ordenamiento de la ciudad moderna, su sentir sobre el espacio urbano parece no contar, así la memoria colectiva de los personajes se ve arrasada, en el barrio amado ya no hay nada que apreciar, los lugares cargados simbólicamente han desaparecido, el que era su pedazo de ciudad ya no les pertenece:

También allá, onde fuera, pues tumbaron la Plaza y empezaron las reformas, porque nos llevó el ensanche. Así decimos desde que volvieron anchas las calles estrechas, nos llevó el ensanche. ¿Dónde está mi barrio, mi cuna maleva, / dónde la guarida, refugio de ayer? / Borro el asfalto de una manotada / la vieja barriada que me vio nacer, dice «Puente Alsina». Lo único que conozco, tangos y perrerías. Y este barrio de Guayaquil, pregunte no más, le sé todas sus cosas. Las que no sepa se las invento. (38)

\section{La ciudad, un desalojo simbólico}

El relato de Medellín en la obra de Mejía Vallejo nos muestra de manera drástica y decidida el modo en que la ciudad se va vaciando de los sentidos que le permiten mantener una conexión con sus habitantes. Como si una fuerza la empujara a solo pensarse a sí misma, la urbe se desconecta de la naturaleza que la circunda, no se pregunta por las consecuencias de la edificación ni le preocupa que el habitante no encuentre un lugar que lo identifique. El proyecto modernizador actúa de la misma manera que un programa para amansar los impulsos, este tipo de 
planificación de una ciudad le da la espalda a todo aquello que sucede por naturaleza, es una imagen del tan comentado combate entre civilización y barbarie: “Allá lo que llaman río, canalizado, domesticado, cruzado de puentes, vena de la ciudad, razón de lo que no hace mucho fue aldea" (Las muertes 209). En las novelas aparece, en repetidas ocasiones, el contraste entre la artificialidad de una arquitectura poco orgánica que se deshace de la sabiduría tradicional y la observación del medio ambiente para ser más rápida y rentable, frente al paisaje montañoso, cultivado y campestre que aún rodea el valle: "Allá los quiebres de las montañas que rodean y refrescan la ciudad. Pinares, eucaliptales, plataneras, cabuyales, humo en las cabañas, riachuelos, torres de radio y televisión, sol y sombra en los repechos, nubes sobre los conos, viento. Y el cielo arriba, inacabable, para tragarse los estruendos que producimos nosotros, estas cosas humanas..." (Mejía Vallejo, Las muertes 210). Lo que hay dentro y fuera de la ciudad se va contraponiendo a medida que se tecnifica el espacio público y se rediseña el espacio privado.

En el ámbito citadino el espacio de la intimidad por excelencia es la casa, la cual no se libra de ser intervenida por la modernización. La forma de habitar la casa, el refugio proyector, se modifica a partir de una novedosa propuesta de construcción que permite dar techo a más personas pero que también cambia por completo las dinámicas vecinales y las costumbres hogareñas: “«Propiedad horizontal» la llaman. Dos cuartos para mi aburrimiento, y cabida para aburrimientos vecinos. O lejanos" (Y el mundo 34). Se planifican lugares para asilar obreros industriales, no se piensa en hogares para vivir según las costumbres familiares o socioculturales. Las casas unidas a la tierra, donde la luz y las plantas se integran con el ambiente íntimo, ya no tienen cabida en las ciudades en crecimiento. Se desecha el terreno para las huertas, se prohíben las jaulas con pájaros, el espacio destinado a la cocina se reduce. La altura de los edificios y la cantidad de gente que puede vivir en ellos son proporcionales al grado de modernización de una urbe, de ahí que se compita por tener el rascacielos más alto. Así Medellín es representada como una ciudad planificada desde la técnica de la 
construcción, que responde al problema de la vivienda sin tener en cuenta las maneras de habitar, culturales y subjetivas. La aplicación de la técnica por la técnica deja por fuera lo humano: "Aunque ahora se habla de cosas exactas, desconfío de las cosas exactas porque deshumanizan. $\mathrm{Y}$ al deshumanizarse, el hombre se convierte en un ser absolutamente peligroso: lo perfecto llegaría a ser una traición a la simple condición humana" (11). Nuestro escritor coincide con Gaston Bachelard al comprender que en la construcción de la metrópoli industrializada y calculada todo se despersonaliza: "El número de la calle, la cifra del piso fijan la localización de nuestro «agujero convencional», pero nuestra morada no tiene espacio en torno de ella ni verticalidad en sí. «Sobre el suelo las casas se fijan con el asfalto para no hundirse en la tierra». La casa no tiene raíces" (Espacio 58). La horizontalidad que propone la nueva arquitectura se acopla al lenguaje simbólico, donde la posibilidad de sentido se alcanza en lo vertical que une cielo y tierra, la construcción queda así despojada de significantes: "Gran cosa esto de la Propiedad Horizontal, ha hecho horizontales y planas nuestras vidas" (Mejía Vallejo, $Y$ el mundo 37). Vivir en el piso más alto no equivale a vivir en la cima de la montaña que alcanza lo celeste, es estéril habitar en ese espacio aferrado a nada. Nos dice Bachelard que a las habitaciones de una vivienda metida en un alto edificio les falta uno de los principios fundamentales para conseguir los valores de la intimidad, pues "a la ausencia de valores íntimos de verticalidad, hay que añadir la falta de cosmicidad de la casa de las grandes urbes. Todo es máquina y la vida íntima huye por todas partes" (Espacio 58). A la casa como nido protector y albergue íntimo también se la lleva el ensanche. La vivienda moderna, al no tener en cuenta ni hábitos, ni rutinas, ni prácticas pierde la armonía con el entorno, se desconecta del cosmos simbólico de los seres humanos, para quienes el mundo va quedando vacío:

Un vaho cálido sale del pavimento, pequeñísimos remolinos levantan el polvo de la construcción vecina: los arquitectos continúan dañando la ciudad, si la ciudad en sí ya no es un daño: no el viento libre sino un opaco viento de ventiladores; no el aire junto a la flor sino la asfixia en las calles 
prisioneras; no el agua capaz de retratar un monte o precipitarse para formar espumas, sino agua obediente, domesticada por el hombre en una simulación de agua... Cajas gigantescas de fósforos en cemento armado, presunción de nuevo rico, del culturalmente desubicado. Serán más largas y torpes las sombras de tantos rascacielos.

-Refugios para las fieras. Todos los días construyen nuevas cárceles, como vivienda. Dejan de entender que la casa es la habitación del hombre y no la cueva del tigre; el lugar donde habita el amor, o la desolación, o la rabia, con sostenes altos para el júbilo y la desesperanza, con amplitud suficiente para nuestras soledades. La casa debería ser el sitio donde uno quisiera vivir y donde quisiera morir, con sus fantasmas propios, con sus vaguedades, con su aire y su fragancia -otra palabra echada atrás- y con el deseo de permanecer ahí para integrarse al barro de donde procedemos. (Mejía Vallejo, Y el mundo 117-118)

La ciudad se nos presenta en lo público y en lo privado como un ente acoplado a ideales netamente económicos, un mundo que impone tareas y deseos a sus habitantes: "Trastos, cuadernos, libros de estudio, listas de mercado, recibos de alquiler, palabras de futuro incierto" (38). El desarrollo no se vive como un proceso orgánico de irse adecuando a las necesidades y los símbolos de una cultura, sino como la imposición de un modelo artificial que va destruyendo los vínculos del ser humano con el espacio que recorre diariamente, generando así una forma de desalojo: "La mirada se alzaba al cielo, regresaba cansada de tan largo viaje. Calles arriba, calles abajo, la ciudad indiferente a las pequeñas parcelas de hambre" (38). La Medellín que acogió a los campesinos y les dio oportunidades, esa metrópoli que fue construyéndose a la par que ellos se alejaban del campo y comenzaban a amarla, ya no tolera que alguien no se sume a su voluntad de ser moderna, tecnológica e industrial: "No todos, ¿ve aquellos?, puros espantos. Les tumbaron su barrio, sus putiaderos. La Plaza. Recuerden los caballos resabiados a la pesebrera, así se resabiaron estos a sus sestiaderos" (Aire 19). Este tipo de habitantes sienten que han perdido su lugar en la ciudad, no hay nada que los 
represente, las zonas se han transformado de tal manera que ya no logran sostener el sentido simbólico que les habían asignado. Todo lo que encarnaba el arraigo a la ciudad ha sido demolido, y en esa demolición se van sus propias raíces, no hay soporte vital y simbólico que permita continuar en ese espacio, todo ha sucedido tan rápido que no hay tiempo para resignificar las transformaciones, el sujeto no encuentra asidero, siente que comienza a morir:

A estas alturas no hay tiro, ya estoy pidiendo pista, ni con quien hablar encuentro. [...] Si uno se para en la esquina, el primer perro que pasa alza la pata y lo mea. Vean, volví al barrio como quien va a un cementerio, ¡espantos que le salen a uno! Resulta de que [sic] tampoco estaba la casa de Jairo ni los mejores cafés que recorrían la plaza ni los compañeros. Las calles ya no son las mismas, ¡nos comió el ensanche! A uno le quitan sus sitios, en esta edá es como si lo remataran. (232)

Medellín se hizo ciudad porque el crecimiento urbano lo demandó, Mejía Vallejo traza su perfil como el de esa urbe que es posible gracias a las constantes y diversas migraciones. Entrar en Medellín y sentirse ciudadano significa para muchos personajes replantear sus símbolos primordiales. Quizá algunos habitantes se resignan y acomodan su vida a las nuevas imposturas o soportan la vida en la periferia social, pero el movimiento no se detiene, casi como en el sentido del eterno retorno, cada cierto tiempo llegan a la ciudad nuevos desplazados con la esperanza de hacer realidad aquella promesa que afirma que la vida citadina es mejor y es la que se debe elegir. A quienes quedaron rezagados en este proyecto modernizador se suman los nuevos migrantes, personas que vienen de zonas que sufren conflictos recientes, trabajadores de la tierra que ahora necesitan un empleo para subsistir. La Medellín moderna no abre sus puertas nuevamente a seres de modales poco refinados que se construyen casas de bareque en las laderas de las montañas y no tienen experiencia para trabajar en las fábricas. Ellos, a pesar de no sentirse a gusto en la ciudad, no tienen más alternativa, de mil formas intentan encontrar su propio 
espacio. La ciudad se arma como una colcha de retazos, producto del desalojo constante, de la imposición de morales y prácticas:

Habían llegado de todos los sitios, de todos los climas, de todas las razas, con heterogeneidad de colores y costumbres que hacían inabarcable el panorama. El pescador sin su ocio, el pueblerino sin su tiempo lento. Se calzó el descalzo, se enjauló el libre, se civilizó el salvaje, se vistió al desharrapado, se apeó el jinete. Pero nadie llegó a ser completamente ciudadano a pesar de querer olvidar lo que antes fuera, traducido en impotencia, rabia, aburrimiento. (Las muertes 208)

Mejía Vallejo refleja una ciudad que está viviendo una fractura, el espacio se organiza según dos mundos diversos. Por un lado, están quienes se han sumado al ideal del progreso e intentan cumplir con sus funciones de empresarios o empleados, sus créditos de vivienda, educan a sus hijos en escuelas privadas y se convierten en una especie de burguesía que integrará las élites. Por el otro, están las personas que no tienen un empleo fijo, que viven en condiciones de pobreza en pensiones o barrios a las afueras de la ciudad, ellos conformarán la clase popular cuya forma de vida no compagina con lo esperado en una ciudad modernizada: "Regueros de automóviles por las avenidas, regueros de gente buscando, buscándose, cuando se afanan por llegar o cuando su meta es cualquier esquina" (La sombra 124). Este cambio social impone un discurso histórico de ruptura, el estado pierde el control de ciertos sectores de la ciudad y se culpa a las migraciones de haber traído la violencia y la delincuencia, sin embargo, estas situaciones no son específicas de esta parte de la población, toda la sociedad se ve envuelta en una profunda crisis, embrión de lo que en pocos años será el fenómeno del narcotráfico, con todas las implicaciones que trajo a la vida de Medellín (Calvo 81). El tráfico de drogas dio dinero y poder a la clase popular, le permitió adquirir la riqueza que la diferenciaba de las clases sociales altas, parte de la élite hizo pactos para no perder su lugar, pero la desconfianza de unos y otros es inmensa. El pacto social que estaba fracturado se rompió, en el medio quedan otros ciudadanos que no 
logran escapar, de nuevo el desalojo se hace efectivo. Pero este fenómeno solo es intuido por nuestro escritor, quien apenas lo vislumbra, este quedará para que otras novelas y otros autores se ocupen de él.

\section{Nostalgia, resistencia y recuperación del espacio perdido}

Los personajes que habitan la ciudad narrada por Mejía Vallejo hablan desde el recuerdo. Para ellos no hay manera de detener el crecimiento desbordado, no pueden atajar esa transformación sin sentido del espacio citadino, la única forma que encuentran para contener esta fuga es la memoria: "Para el hombre sobrevivir, el recuerdo es tan importante como el sueño y la ensoñación: solo ellos complementan lo de hoy; sin ellos, objetos, personas y tiempo serían simples cosas mutiladas" ( $Y$ el mundo 9). El recuerdo se asume como el medio de reconstrucción más efectivo porque permite reanimar los afectos asociados a las situaciones o los paisajes devolviéndoles su lugar vital. Cada demolición, cada ampliación, cada nuevo edificio es registrado como una pérdida significativa, en su desaparición no solo se modifica el espacio urbano, con ellos se esfuma la constancia del espacio que da soporte real a las historias personales: "Los años serían bellos vistos de perfil. Sombra de presencias en su sombra junto a la sombra de los edificios de una ciudad que nos destruyeron, en unas esquinas y unos ámbitos que tratan de atestiguar su vocación de fantasmas" (9). Como hemos estado argumentando, al emerger la metrópoli moderna se fractura la relación que se ha establecido con el espacio habitado, el territorio se presenta como ajeno y se necesita más que un proceso de adaptación para volver a sentirse parte del espacio, además se debe asumir la pérdida de aquellos lugares que se consideraban fundamentales.

En esta Medellín de la ficción, la identidad del sujeto se encuentra interrogada, de ahí que la memoria venga como una tabla de la cual asirse para salvaguardar lo poco que queda. La evocación funciona a manera de resistencia ante la idea del progreso, esa visión que desconoce la continuidad del pasado que 
fundamenta lo originario, que solo valora lo nuevo, que se afana por propagar el discurso de una innovación que borra y quiere deshacerse de esto que se vive hoy pensando solo en el mañana que nunca llega. Volver al tiempo en que todo comienza, rearmar los símbolos primeros es la tarea que emprenden estos personajes, quienes cuentan su vida al otro, se quejan del funcionamiento de las calles, de la desproporción de las construcciones, hacen listas de nombres y lugares que ya no están o que son otros: "El Barrio -Manrique, Aranjuez, La América, Boston, Buenos Aires, San Benito-, sus tejados grises y la locura y la poesía [...] El Barrio, donde la vida limita con todos los puntos cardinales" (Mejía Vallejo, La sombra 80-81). La fascinación que genera la novedad propia de la curiosidad y ambición humana se interroga con la pregunta por el origen, el recuerdo como ritual hace las veces de escudo ante el progreso arrasador. De ahí que los personajes retomen imágenes de su infancia:

Cuando llego a estos sitios recorridos de mi infancia, antes de transformarlos en espectaculares edificios, siento algo mío en el ambiente, la presencia austera del abuelo, mi padre en su aprendizaje de jefe, primos hermanos entre los matorrales. Era más vegetal el paisaje, más humano. De una ladrillera queda esa hermosa chimenea que levanta su agresiva y solitaria extemporaneidad. (Las muertes 168)

El tono de ese rito que actualiza el pasado es el tono de la nostalgia, pocas veces aparece una evocación sin ese punto triste de anhelo que hace sentir que el tiempo pasado era mejor, y que contrasta con esos momentos en que las historias de los personajes dan cuenta de lo contrario, pues llegaron a Medellín huyendo de la violencia, pobres, expropiados, fueron explotados por la industria y la desigualdad. La recreación del pasado feliz y dichoso es una ensoñación necesaria para dar consistencia al presente a través de entenderse en la imagen del antepasado, de los valores que se han vivido y defendido. A veces los personajes reconocen que hay invención en lo que evocan, hablan de mentira aunque no de falsedad, porque a esas reminiscencias creadas el sentimiento les da legitimidad: “-Hay cosas que 
no se pueden olvidar / -Cuando salgas de esas mentiras... -amonestó mi primo. Sabía que a veces, por comodidad, yo trataba de vivir en forma de recuerdo, que me fugaba, como ahora, en acto de legítima defensa" ( $Y$ el mundo 47). Tal como explica Bachelard, la ensoñación de imágenes trae consigo una verdad subjetiva, tiene una raíz que impide cuestionar su veracidad así esté adornada con invenciones, palabras o escenas inventadas, por tanto, "la imagen es nueva, siempre nueva, pero la resonancia es siempre la misma" (Ensoñación 302). La nostalgia estimula la ensoñación, es una forma de imaginación sentida y estimulada por los recuerdos que encuentran un camino de regreso. Para quienes caminan por esta Medellín la nostalgia es quizá un afecto que rescata, en tanto permite la recuperación de un tiempo perdido y protege de insertarse ciegamente en la lógica de avanzar por avanzar:

A veces uno tiene vergüenza de sus abuelos, necesidad de justificarlos en lo mejor que lleva; don Cosme resucita tiempos de la aldea-ciudad, aunque sigue viviendo como si ella no hubiera crecido, más lejana de la actual que de aquella en los primeros tiempos de la fundación.

Porque este fue el valle de los Aburraes, alfareros y tejedores que se ahorcaban con sus mantas por el bien perdido y por las barbas de aquellos infernales centauros; este fue asiento de los primero pobladores blancos [...] Después años y años, polvo en los huesos, destierro de la selva, huida del aborigen, edificaciones, polvo, polvo, polvo.... (Mejía Vallejo, Las muertes 298-299)

En los habitantes que nos relata Mejía Vallejo apremia una necesidad de retomar los tiempos primeros, de volverlos a narrar intentando reconocerse en esas imágenes: “¿La vida se nos va pero el momento queda!” (Aire 124). El camino de la nostalgia es un sendero por el que se encuentran los retazos con los cuales responder, una y otra vez, a la pregunta por la identidad. Esos pedazos dan luz por un instante y vuelven a escapar dejando un silencio que necesita de nuevas evocaciones: "Pueden sacarse cosas nuevas de los recuerdos, por más que se saque 
siguen llenándose de güecos de onde los cargamos" (55). Esta necesidad de mantener viva la llama de la memoria es la que explica el lugar de la música, de las canciones, en este retrato de Medellín. Las novelas están cargadas de letras de melodías populares, el bambuco y el pasillo resaltan el ambiente melancólico de muchos momentos, pero es el tango el que consigue cantar realmente los lugares de la ciudad habitados por estos personajes: "Tal vez uno no tenga penas en ciertos momentos, pero el tango trae las suyas y nos las presta" (117). Según el análisis de Paola Fonnegra sobre la ciudad en la obra de nuestro escritor, entendemos que "el tango referencia lo perdido, lo popular, lo que no está juzgado desde las reglas morales, nace en la marginalidad y es a ella a quien poetiza. El tango es un canto a la soledad, al amor, al hombre mismo, sus letras permiten lo que la vida cotidiana niega, en el tango el más macho de los hombres llora porque es digno llorar cuando se ha amado" (64). La canción en la narrativa de Mejía Vallejo es una representación más del recuerdo, su función es de evocación, la música para él fija instantes que tiempo después hacen presencia, justo cuando vuelve a sonar la melodía.

Medellín sigue viva en estas novelas porque aún se escuchan canciones, porque aún se recuerda, pues el olvido es la muerte. Cuando el ensanche arrasa con las calles impone un silencio, acalla los sentidos, destierra las guitarras e interrumpe la conversación de las cantinas que se cerraron. Los personajes manifiestan constantemente el temor a perderlo todo definitivamente, a extraviarse en el olvido, esa imposibilidad de volverse a narrar que lo sepulta todo: "Y este corazón seguirá golpeando contra el oficio inútil de vivir en los recuerdos, algunas quejas se alzarán en las tumbas hermanas. Todo lo arrasará el olvido" (Las muertes 350). Es este el peligro de las calles que se ensanchan, que borran lo que se ha sido e invitan a no mirar hacia el pasado, su bandera solo apuesta al futuro, que es un porvenir incierto, un tiempo que no se ha cantado, que no tiene memoria porque se desembarazó de lo que un día fue y que cuesta mucho mantener. Ante ello los personajes piensan que lo importante no es mantenerse vivo sino recordar, trayendo a colación un leitmotiv que atraviesa toda la obra narrativa del escritor: "No importa la muerte, 
que la pelona venga después de lo que hicimos, lo importante es la canción" (Aire 124).

Las novelas adquieren un sentido adicional si tenemos en cuenta lo anterior, no solo son una representación de la ciudad en las décadas del 60 y el 70 del pasado siglo, son además documentos que intentan dejar constancia de lo que un día fue. El escritor toma la misma posición de esos seres que creó en su ficción, su nostalgia lo empuja a rememorar, a dar rienda suelta a la canción que haga revivir las historias de aquellos tiempos. El amor por la ciudad lo invita a no dejar perder el pasado, pues solo este afecto convoca a esta tarea, tal como explica con humor uno de los personajes: "-Yo buscaba el amor. /-Lo atropelló un automóvil a principios de siglo. /-¿No hay salvación? /-Tal vez. /-¿Cuál? /-El amor" (La sombra 81). La novela se puede apreciar entonces como juego de la memoria, reflejo de lo perdido, un acta levantada desde imágenes simbólicas que impiden el arrasamiento último, el olvido. Vale la pena traer unas últimas visiones de esa Medellín tan amada como odiada, centro de las más grandes contradicciones y ambigüedades, valle que solo puede ser entonado desde la nostalgia:

Este es el aire de mi ciudad, este es el aire. Llanto en algún lado, gritos en otro, silencio y pena y esfuerzo y vagancia. Aire de gasolina y humo, de bruma y cielo azul, de montañas verdeamarillas, de tangos y bambucos. Este es el aire para borrachos y regenerados, para víctimas y negociantes de arriba, del medio, de sospechosas alturas, de suburbios caricaturescos [...] Aire de un Dios a imagen y semejanza de la astucia y el terror, acomodado a vivir diario, estrecho en iglesias y oraciones. Es el aire maldito y amable de una ciudad filistea con bahías para un amor y una pasajera muerte. Valle de Los Aburraes anónimos, de culebreros y fingidores, de los duros y generosos, de los cínicos y botaratas. (Las muertes 341) 


\section{Conclusión}

El ensanche se llevó una ciudad, en su reemplazo creó la imagen de otra más cosmopolita, con mayor poder económico, con edificios que intentan equiparar su altura a la de las montañas y un discurso de ruptura social instaurado en el imaginario de los antioqueños. Nuestros personajes son seres desorientados, arraigados a sus recuerdos, sin soporte en el presente, la violencia arrasó con la vida del campo y el progreso les impide la vida en la ciudad, solo les queda su memoria: "En todas las calles veíamos el circo humano, lo duro del olvido, el recuerdo en categoría de valores, la ansiedad y el tedio, la rutina trazada como un pueblo de calles largas y almacenes, de inmovilidades al borde del salto" (Mejía Vallejo, La sombra 81). Todo quedó atrás, no hay futuro, Medellín, el espacio que los alberga, no es para ellos una esperanza, es una reminiscencia, aman lo que ella significó, aborrecen lo que en esos momentos ofrece y esto les impide sumarse a un proyecto conjunto de valores. La Medellín escrita de Mejía Vallejo deja entrever las grietas de una sociedad que ha perdido sus sentidos enfocándose en un afán de progreso, industria y capital. Hablamos de una aldea que cree transformarse para avanzar demoliendo sus espacios simbólicos, aquellos que permitían la conexión entre el lugar y los seres humanos, al punto de quedar vacía de significantes que la lleven a una consolidación de una historia colectiva. Es una ciudad que se asoma al abismo y, sin saber lo que le espera, se arroja decidida a él. La desilusión, la tristeza y la confusión de los personajes son una proyección de lo que vive toda la urbe. Late en sus calles una sensación generalizada de frustración y una amenaza constante de muerte que se traduce en un descenso hacia el olvido. Solo la memoria puede reordenar el panorama volviendo a traer el tiempo que se ha perdido, el que se fue con el ensanche, el que se va con aquellos que acallan sus historias sin dejar rastro. Aquel que el mismo Mejía Vallejo da por desaparecido en la voz de uno de sus personajes: “¿A quién culpar del fracaso mío y de todo lo que me rodea? Ya no estaré para averiguarlo, ¡que lo averigüe El Putas!’ (Y el mundo 15). 


\section{Bibliografía}

Bachelard, Gaston. La poética del espacio. Fondo de Cultura Económica, 2010. . La poética de la ensoñación. Fondo de Cultura Económica, 2011.

Betancur, Jorge Mario. Moscas de todos los colores: barrio Guayaquil de Medellín, 1894-1934. Editorial Universidad de Antioquia, 2006.

Calvo, Óscar. "Hacia una historia intensa de Medellín”. Estudios políticos, no. 44, 2014, pp. 77-85.

Fonnegra, Paola. "La ciudad como elemento de transformación narrativa: una aproximación a la novela Aire de Tango de Manuel Mejía Vallejo”. Katharsis, no.15, 2013, pp. 53-66.

Gallego, Santiago. "La provincia más importante del mundo". Arcadia. 25 oct 2017. Web. 30 nov 2017. https://www.revistaarcadia.com/periodismocultural---revista-arcadia/articulo/antioquia-es-la-provincia-de-colombiaantioquenidad-paisas/65290

Giraldo, Luz Mary. Ciudades escritas: literatura y ciudad en la narrativa colombiana contemporánea. Convenio Andrés Bello, 2001.

Mejía, Clara Victoria. "La novela urbana en Colombia: reflexiones alrededor de su denominación”. Lingüistica y Literatura, no. 57, 2010, pp. 63-77.

Mejía Vallejo, Manuel. Las muertes ajenas. Plaza \& Janés, 1979. . Y el mundo sigue andando. Plaza \& Janés, 1984. . La sombra de tu paso. Biblioteca Pública Piloto, 2002. . Aire de tango. Plaza \& Janés, 2009.

Melo, Jorge Orlando. "Ciudadanía y violencia: algunas notas sobre la experiencia de Medellín”. Boletín Socioeconómico, no. 29, 1995, pp. 21-36.

Orrego, Jaime A. “Ojalá nunca amaneciera: guapos y homosexuales en el Medellín de Aire de tango". Perífrasis, vol. IV, no. 8, 2013, pp. 87-103. Silva, Armando. Imaginarios urbanos. Tercer Mundo Editores, 2006. 